\title{
ANTROPOLOGIA NO CAMPO DA SAÚDE GLOBAL
}

\author{
João Biehl \\ Princeton University - Estados Unidos
}

Resumo: Neste artigo, eu exploro os limites de abordagens baseadas em balas mágicas para os problemas de saúde global e mostro como as iniciativas centradas nas pessoas desafiam as ortodoxias econômicas e dos direitos humanos e ampliam nossa percepção daquilo que é socialmente possível e desejável. Utilizo o meu estudo etnográfico de longo prazo sobre a resposta terapêutica brasileira ao HIVIAIDS e suas repercussões nos âmbitos de governo, mercados, sistemas de saúde e vida pessoal. Faço também o relato de um novo projeto comparativo sobre as consequências de grandes intervenções farmacêuticas em contextos com recursos limitados. Considerando tanto os processos mais amplos quanto as singularidades humanas, o artigo abre uma janela crítica para os valores e os resultados de intervenções farmacêuticas e humanitárias contemporâneas na vida real. Ao criticar as práticas institucionais de produção de evidência, também reconsidero as noções de responsabilidade e cuidado dentro da antropologia e da medicina.

Palavras-chave: etnografia, farmaceuticalização, saúde global, teoria social.

Abstract: In this article, I explore the limits of magic-bullet approaches to global health problems and show how people-centered initiatives challenge economic and human rights orthodoxies and enlarge our sense of what is socially possible and desirable. I draw from my long-term ethnographic study of the Brazilian therapeutic response to HIV/AIDS and its repercussions through government, markets, health systems and personal lives. I also report on a new comparative project on the aftermath of large-scale pharmaceutical interventions in resource-poor settings. Attending to both larger processes and to human singularities, the article opens a critical window into the values and the real-life outcomes of contemporary pharmaceutical and humanitarian interventions. As I critique institutional evidence-making practices I also reconsider anthropology and medicine's notions of responsibility and care.

Keywords: ethnography, global health, pharmaceuticalization, social theory.

* Agradeço a Torben Eskerod por seu poderoso trabalho fotográfico e a Tom Vogl por sua perspicaz ajuda editorial e confecção das figuras apresentadas neste artigo. Agradeço também a Adriana Petryna, Joseph Amon, Amy Moran-Thomas, Alex Gertner, Ari Samsky, Peter Locke e Mariana Socal por seus comentários e auxílio. Agradecimentos especiais a Paula Vargas e Claudia Fonseca. A pesquisa e a redação foram apoiadas pela Health Grand Challenges Initiative e a Woodrow Wilson School of Public and International Affairs na Princeton University, o Center for Theological Inquiry e a Fundação Ford.

Horizontes Antropológicos, Porto Alegre, ano 17, n. 35, p. 257-296, jan./jun. 2011 
É a parte financeira da vida que me tortura.

Eu começo com um poema de João Cabral de Melo Neto (2005) sobre o povo do Nordeste brasileiro, uma das regiões mais pobres da América Latina. João Cabral escreve sobre gente amalgamada naquele ambiente inóspito, porém com uma fluidez sem par, que cria potencial. O poeta cresceu lá e é para lá que eu os levarei neste artigo:

E neste rio indigente, sangue-lama que circula entre cimento e esclerose com sua marcha quase nula, e na gente que se estagna nas mucosas deste rio, morrendo de apodrecer vidas inteiras a fio, podeis aprender que o homem é sempre a melhor medida.

Mais: que a medida do homem não é a morte mas a vida.

A vida é passageira. Sem dúvida, isso era verdade para Evangivaldo. "Que prazer ver você de volta", o homem de 38 anos abriu um grande sorriso quando me viu com o fotógrafo Torben Eskerod em dezembro de 2001 na Caasah, um abrigo comunitário para doentes de AIDS em Salvador. Considerada por muitos "a capital africana do Brasil", Salvador é a capital do estado da Bahia. Na cidade de cerca de 2,5 milhões de habitantes, mais de $40 \%$ das famílias - como a de Evangivaldo - vivem abaixo da linha de pobreza. Eu mal pude reconhecê-lo. Mas os visíveis e desoladores efeitos colaterais das terapias contra AIDS eram o que menos preocupava Evangivaldo. "Hoje eu acordei aflito. Não temos mais gás para cozinhar."

Ajudamos a resolver o problema com prazer e dissemos a Evangivaldo que tentávamos encontrá-lo há três dias, mas tínhamos o endereço errado. "Eu já me mudei quatro vezes. Os vizinhos descobriram que nós temos AIDS", ele disse. "Quando era só a Fátima e eu, dava para improvisar, mas agora que temos um bebê a coisa é diferente. Nós podemos passar fome, mas a 


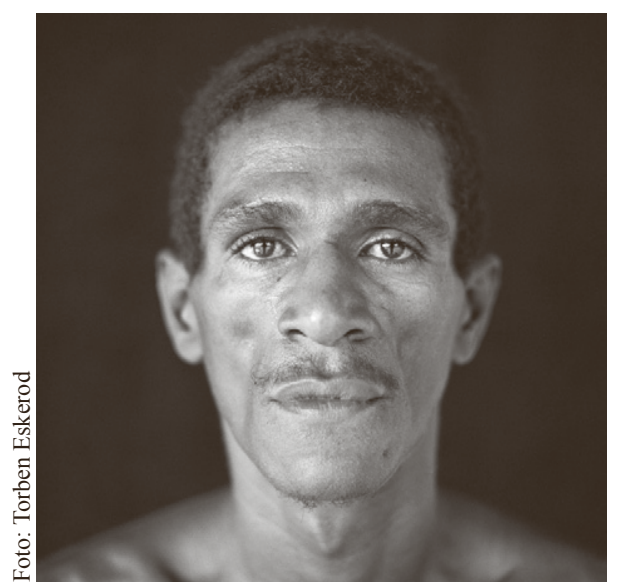

Figura 1. Evangivaldo, 2001.

Juliana não pode. Eu sempre tomo meu 'coquetel' [remédios antirretrovirais], mesmo quando tenho só café no estômago." Evangivaldo explicou que "a gente não tinha planejado ter um filho. A camisinha estourou. Mas, agora que ela está aqui, eu vejo que é o que eu mais queria na vida. Eu pensei que ia morrer... mas agora eu tenho um fruto da terra." Ele fez uma pausa e acrescentou: "É a parte financeira da vida que me tortura."

Através de produtos farmacêuticos e à mercê de uma economia volátil, Evangivaldo e sua família vivem num torvelinho. Como milhões de outros portadores de AIDS pobres em todo o mundo que agora têm acesso a tratamento, ele lutou para escapar do fluxo da história para uma vida prolongada pela tecnologia. Em busca de recursos e atendimento, Evangivaldo fez esforços extraordinários e desesperados para evitar e superar todos os tipos de limites. Ao tentar escapar de uma morte econômica, ele expressava também o desejo de uma mudança do mundo. Este artigo é sobre Evangivaldo e os campos sociais que a nova população de AIDS cria e em torno dos quais organiza suas vidas. Os esforços e as ações dessas pessoas derrubam probabilidades e preconceitos e expandem os limites daquilo que pode ser conhecido e trabalhado no novo mundo/mercado de saúde global.

\section{Modelo de política}

O Brasil responde por $43 \%$ de todos os casos de HIV/AIDS da América Latina. Calcula-se que 730 mil brasileiros viviam com HIV/AIDS em 2007 - uma prevalência adulta de 0,6\% (Gráfico 1). Durante cerca de uma década, o número de novos casos variou entre 20 e 25 por 100.000 por ano para os homens e 10 e 15 por 100.000 por ano para as mulheres. Mas estudos socioepidemiológicos demonstram uma heterogeneidade considerável entre os índices de infecção por HIV, com grande quantidade de infectados entre grupos 
de risco como homens que fazem sexo com homens, profissionais do sexo e usuários de drogas injetáveis. O Brasil é realmente conhecido por uma terrível desigualdade social e problemas crônicos de crescimento. Ainda assim, contra todas as chances, o Brasil inventou uma maneira pública de tratar a AIDS.

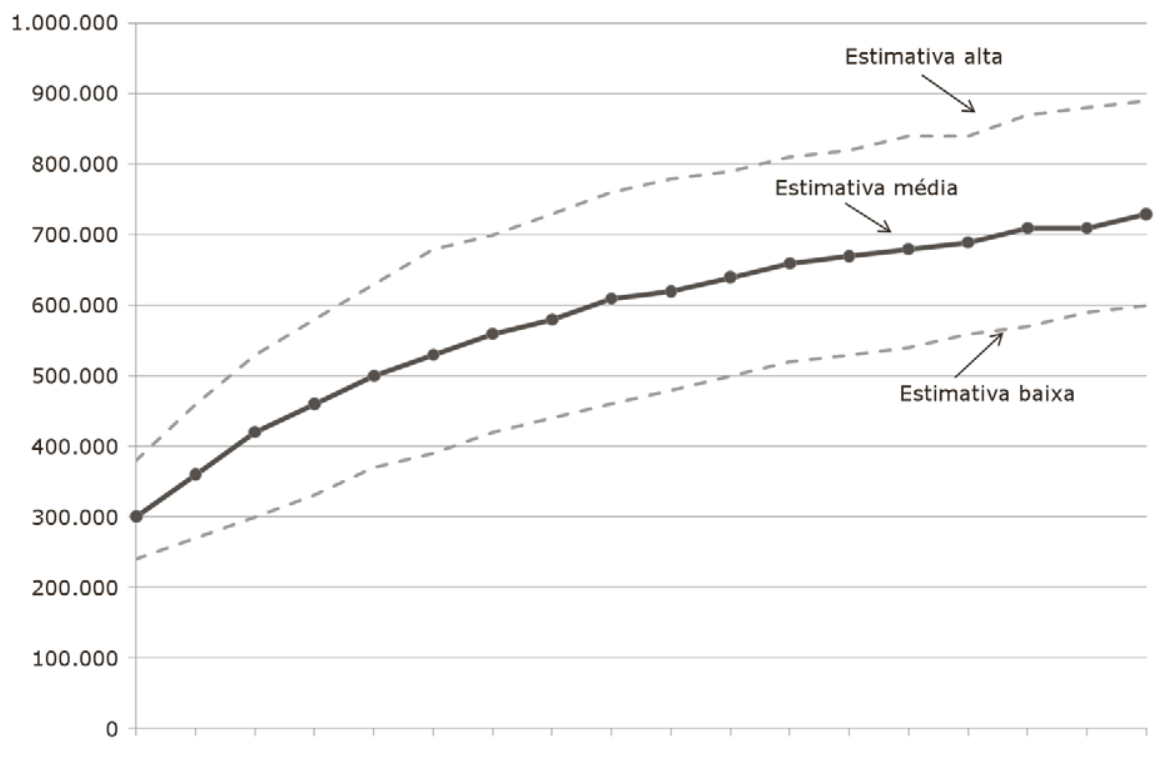

199019911992199319941995199619971998199920002001200220032004200520062007

Fonte: Nações Unidas.

Gráfico 1. Número de pessoas vivendo com HIV, Brasil.

No final de 1996, uma legislação pioneira garantiu acesso universal à terapia antirretroviral (Gráfico 2). Essa política foi resultado de uma poderosa mobilização social baseada em direitos e novas parcerias público-privadas. A Constituição democrática de 1988 garantiu a todos os cidadãos o direito à saúde e determinou a criação do sistema nacional de saúde - os ativistas da AIDS foram o primeiro grupo a efetivamente utilizar esse direito para acesso a 
medicamentos. Cerca de 200 mil brasileiros atualmente utilizam antirretrovirais pagos pelo governo. O governo conseguiu reduzir os custos do tratamento através do incentivo à produção de genéricos. Ao mesmo tempo, negociou substanciais reduções de preço com as companhias farmacêuticas.

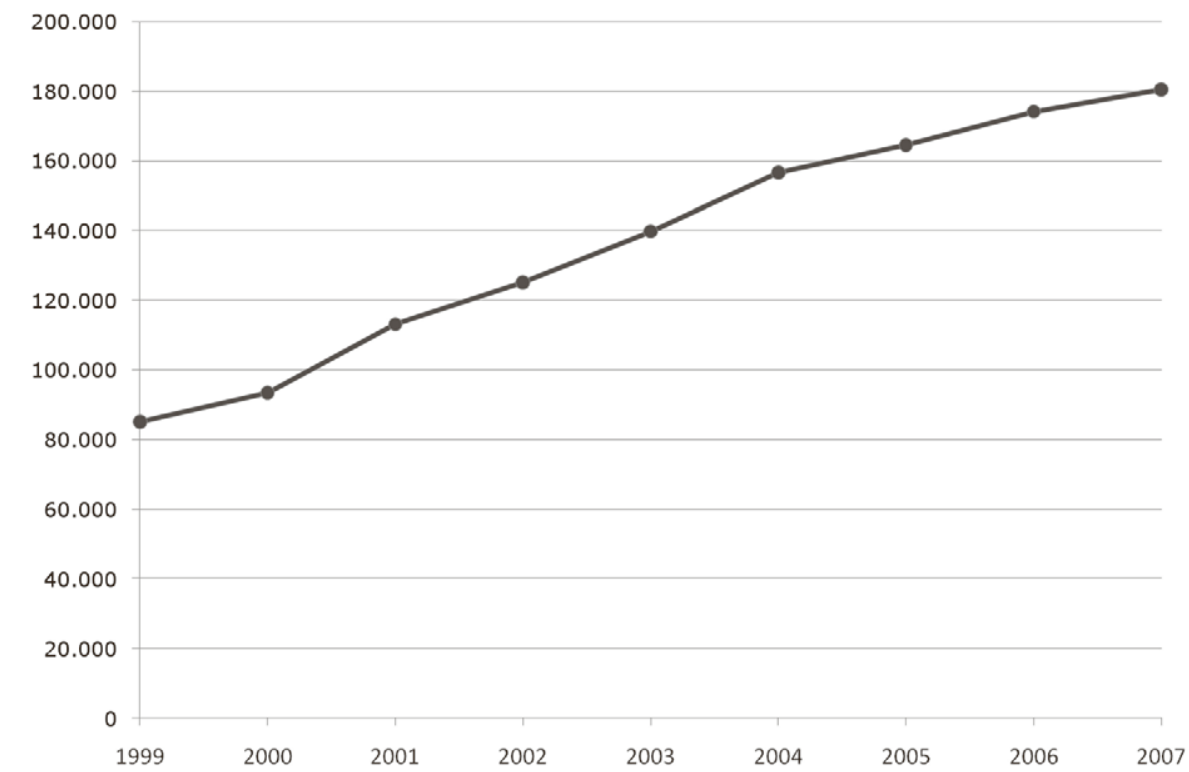

Fonte: Ministério da Saúde.

Gráfico 2. Número de pacientes recebendo terapias antirretrovirais, Brasil.

De acordo com o Ministério da Saúde, tanto a mortalidade de AIDS quanto o uso de serviços hospitalares por AIDS caíram mais de 50\% (Gráfico 3) após a introdução dessas terapias. Talvez ainda mais impressionante seja o declínio da mortalidade no primeiro ano pós-diagnóstico (Gráfico 4), demonstrando a transformação do HIV/AIDS de doença grave para uma doença crônica. A ousada resposta terapêutica do Brasil à AIDS, em grande escala e com múltiplos 


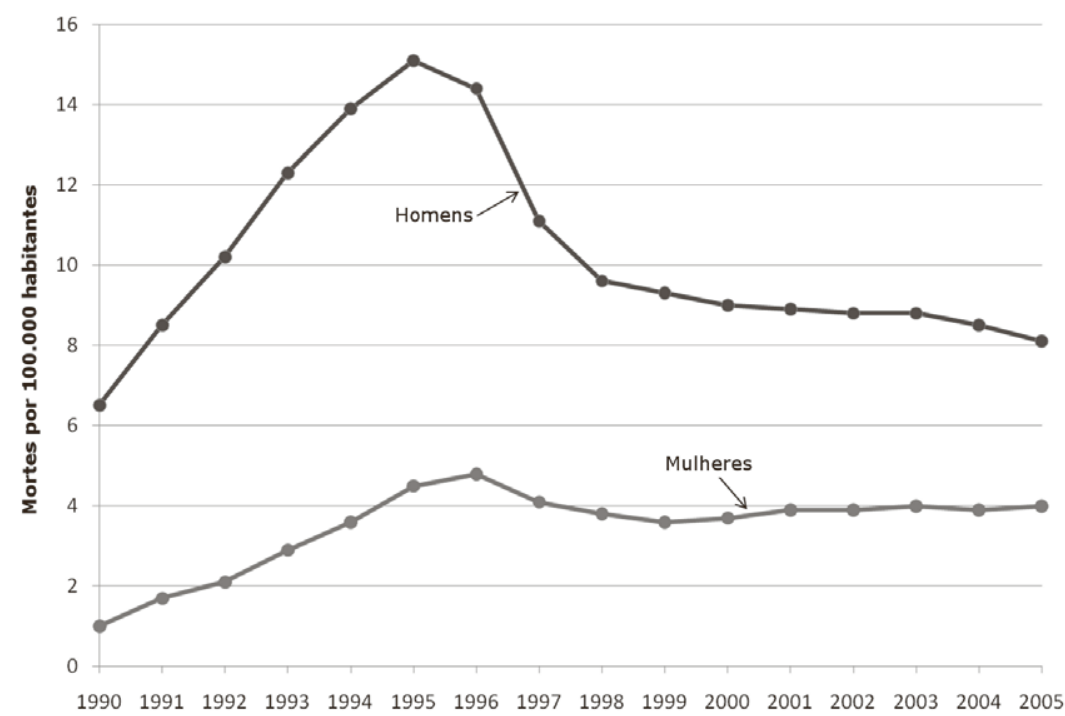

Fonte: Ministério da Saúde.

Gráfico 3. Mortalidade por AIDS, Brasil.

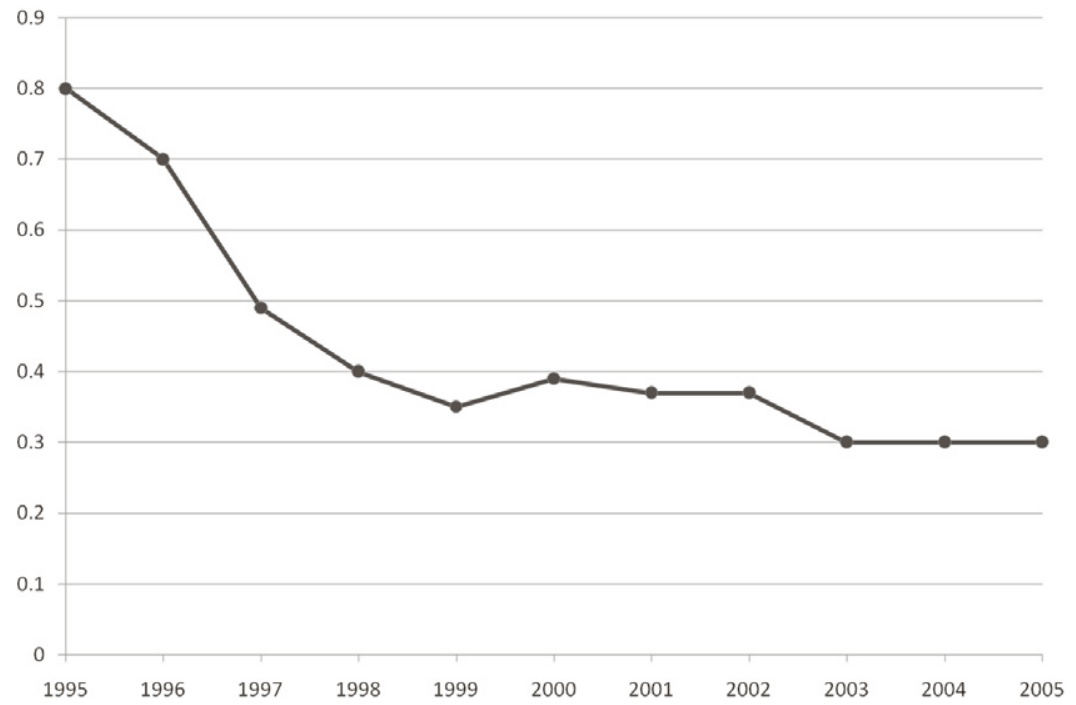

Fonte: Ministério da Saúde.

Gráfico 4. Mortalidade por AIDS no primeiro ano após diagnóstico, Brasil. 
atores, fez história (Gráfico 5). Ela desafiou empiricamente a pretensão das ortodoxias médicas e econômicas de que tratar a AIDS em contextos com recursos limitados seria impraticável e que doentes pobres não poderiam seguir esses complexos regimes terapêuticos - por essa razão, o Brasil tem sido um líder no esforço para universalizar o acesso às terapias de AIDS.

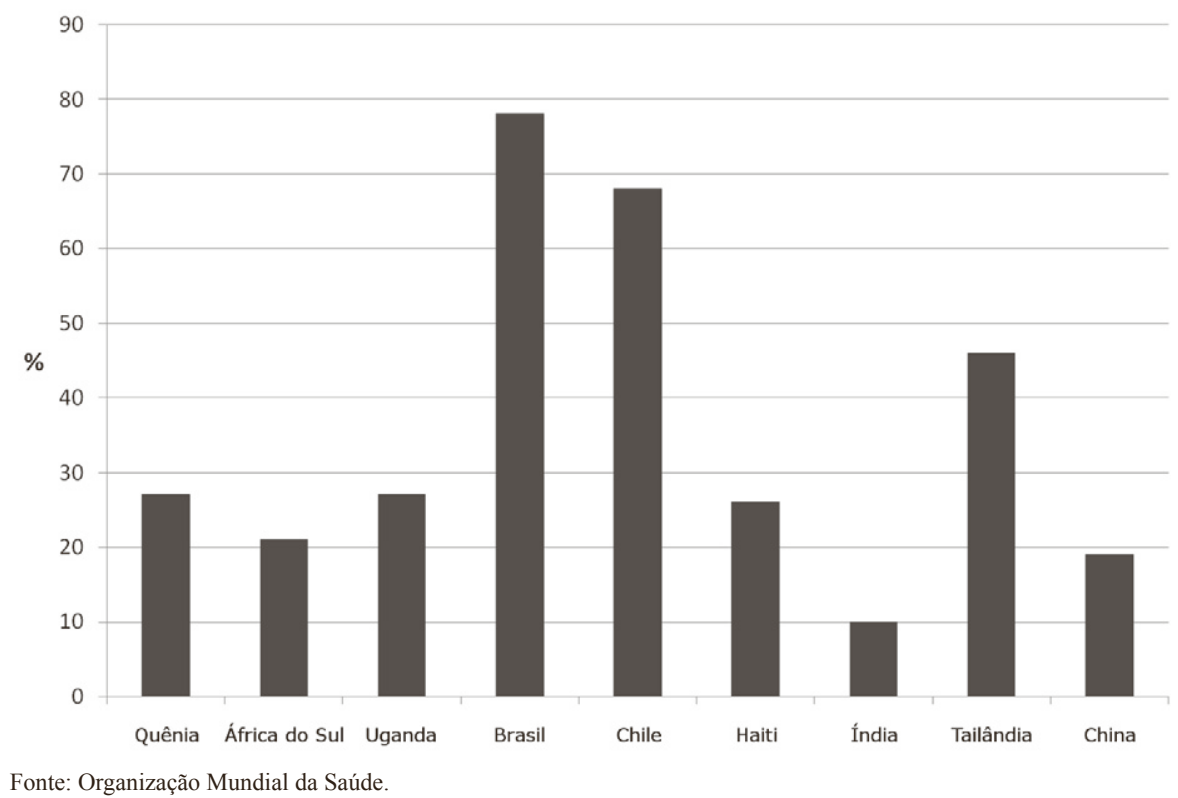

Gráfico 5. Acesso a Terapias Antirretrovirais para pessoas com HIV/AIDS, 2006.

Mesmo assim, eu me perguntei, que efeitos teria a política de tratamento universal sobre os cidadãos mais pobres e marginalizados do país, entre os quais o HIV/AIDS se espalhava mais rapidamente? De que maneira as pessoas como Evangivaldo e Fátima transformariam uma sentença de morte em uma doença crônica? Que inovação social poderia tornar possível tal transformação médica? 


\section{Na direção do incompleto}

Por mais de dez anos, eu examinei o impacto da inauguração do tratamento da AIDS em todas as instâncias de governo do país, sistemas de saúde e vidas pessoais. Entrevistei criadores de políticas públicas e profissionais da saúde e conduzi um estudo de longo prazo com doentes de AIDS marginalizados em Salvador. Ao mapear as vidas de doentes pobres antes e depois de eles terem acesso aos antirretrovirais, eu quis abrir uma janela para os resultados das novas políticas nacionais, internacionais e corporativas na vida real (Biehl, 2007). De modo geral, tenho me interessado pelas artes de governo que acompanham a globalização econômica e a reconstrução de pessoas como segmentos de mercado (especificamente, mercados terapêuticos). Como os pacientes-cidadãos agem para ter acesso a recursos do governo enquanto negociam os caprichos do mercado e a sobrevivência? Quando e sob que condições as pessoas marginalizadas são consideradas população-sujeitos nos novos regimes biomédicos?

No meu trabalho etnográfico, interagi também com comunidades não governamentais e farmacêuticas que atenderam ao apelo por responsabilidade e atendimento diante da AIDS. Seguindo o exemplo do Brasil, há iniciativas sendo deslanchadas hoje que buscam abordar a AIDS terapeuticamente em lugares onde quase não havia tratamentos disponíveis. Se no passado o campo da saúde pública internacional foi dominado por organizações multilaterais e bilaterais, surgiu agora uma complexa matriz de parcerias (não governamentais, filantrópicas, industriais e governamentais) que está modelando intervenções de saúde no mundo inteiro sob a forma de segurança e humanitarismo (Fidler, 2008) - o campo do tratamento global da AIDS é paradigmático dessa tendência.

As parcerias público-privadas em saúde global vêm em variadas formas e seus interesses são os mais diversos. Variando da Fundação Gates, aos programas corporativos de doação de remédios, ao PEPFAR (plano presidencial dos EUA para combate à AIDS), aos projetos-piloto como os "Partners in Health" - Parceiros em Saúde - no Haiti e em Ruanda, esses vários atores têm relacionamentos elásticos uns com os outros. Eles estabelecem metas e novas formas de ação institucional e às vezes preenchem o vazio em lugares onde os mercados e os sistemas nacionais de saúde estão deixando de atender 
às necessidades de saúde pública ou estão completamente ausentes (Reich, 2002). Sejam quais forem as diferenças entre as agendas de saúde corporativas, ativistas e públicas, a nova rubrica de "valor" parece reconciliar essas diferenças, encerrando-as num ethos de responsabilidade coletiva. Talvez os participantes possam tornar-se insensíveis às críticas quando apontam para péssimas estatísticas de saúde global e seu dever não opcional de agir (isto é, para colaborar, tornando o tratamento acessível e salvando vidas - ver Sachs, 2005; Singer, 2009).

Até agora, poucas instituições estão posicionadas para monitorar esse crescente e relativamente desordenado campo de "bens públicos" (Biehl, 2008; Samsky, 2009). Na prática, os interesses e preocupações dos doadores, não dos receptores, tendem a predominar e as operações das organizações internacionais tendem a reforçar as existentes e desiguais relações de poder entre países (Banerjee 2005, 2007; Epstein, 2007; Ferguson, 2006; Ramiah; Reich, 2005). Além disso, as iniciativas são cada vez mais dominadas por medidas de avaliação cientificamente fundamentadas, que giram em torno de experimentos naturais, ensaios randomizados e controlados, significância estatística e custo-efetividade (Duflo; Glennerster; Kremer, 2008; Todd; Wolpin, 2006) - uma retórica técnica alinhada com a exigência de soluções técnicas por parte das organizações financiadoras. As iniciativas de saúde pública tradicionais são agora listadas na categoria de "não ciência" e essa "preocupação científica" tende a desconsiderar a dinâmica dos programas na prática, presumindo que eles funcionarão em outros cenários, repletos de diferentes instituições, práticas e racionalidades (Adams; Novotny; Leslie, 2008).

De fato, muita coisa é deixada de lado, escapando a qualquer debate, nessa forma global de experimentalidade e "pós-política" (Ecks, 2005; Petryna, 2009). Como obrigar doadores a prestar contas a longo prazo, especialmente nesta época financeiramente volátil? Como as tendências de saúde global afetam o papel dos governos e suas obrigações com os direitos humanos? Além disso, como estão sendo tratadas as outras doenças mortais da pobreza que têm menos apoio político? Que projeções e sistemas de valor subscrevem as decisões políticas e a triagem médica? Problemas e questões que não eram necessariamente previstos e que agora têm de ser tratados como imperativos para salvar vidas foram transformados em novo capital geopolítico e farmacêutico.

No seu livro recente Cold War, deadly fevers, o historiador Marcos Cueto (2007) documenta a história por trás do programa de erradicação da malária 
que teve um papel crucial na política de saúde pública do México durante os anos politicamente tensos na época da Guerra Fria. Sem nunca perder de vista as implicações políticas internacionais da campanha, o relato detalhado de Cueto (2007) sobre como o programa de erradicação se desenrolava na prática leva-o a terrenos antropológicos inesperados: ele documenta uma profunda desconexão entre como a campanha foi projetada pela Fundação Rockefeller e a elite de especialistas nacionais em saúde, e as complexas maneiras como ela foi realmente recebida pelos residentes indígenas do México rural. Em comunidades rurais, muitas famílias simplesmente não deixaram os aplicadores de DDT entrar em suas casas, e houve casos em que o protesto espontâneo chegou às raias da violência armada. Vários anos depois, até mesmo pessoas que haviam concordado com as primeiras aplicações de DDT notaram com raiva que a medida era cada vez menos eficaz, e que muitos insetos já pareciam estar desenvolvendo resistência e ficando maiores em vez de morrer.

Foi nesse tenso momento histórico que a antropologia médica surgiu como ciência aplicada. A antropóloga Isabel Kelly, ex-aluna de George Foster em Berkeley, começou a colaborar em projetos rurais com Héctor García Manzanedo e a Secretaria de Saúde Mexicana em 1953. Quando os dois começaram a investigar como o programa de erradicação da malária estava sendo recebido em comunidades indígenas, conceberam seus papéis como sendo os de ouvintes e corretores culturais. O relatório deles sugeria inúmeras e complexas razões, que iam muito além das já subestimadas barreiras linguísticas, sobre o porquê de o programa não estar alcançando o sucesso esperado. Por exemplo, os relatórios dos antropólogos descreveram padrões complexos de rotação de moradia segundo as estações, mostrando que as famílias muitas vezes sazonalmente abandonavam a casa que tinha sido dedetizada ou simplesmente preferiam dormir do lado de fora no calor do verão. Mais fundamentalmente, com frequência as comunidades indígenas mantinham seus próprios sistemas de cura e entendimentos sobre a febre, em desconfortável coexistência com a informação de saúde pública sobre malária distribuída pelo governo. E, como os antropólogos lembraram finalmente, esse ambiente de suspeita era sustentado por uma diferença fundamental de prioridades de saúde. Em muitas comunidades, a malária não era considerada um grande problema de saúde ou mesmo uma doença em si, e muita gente nas áreas rurais se perguntava por que davam atenção a isso enquanto outros problemas de saúde mais urgentes eram ignorados. 
A complexa descrição de Cueto (2007) capta o fato de que essa colisão entre valores locais e agendas internacionais de saúde pública não foi nem de longe um mero acaso ou uma nota na história da erradicação da malária - foi uma das principais causas do fracasso final da campanha. Sem prestar atenção a como essa intervenção passou a integrar as economias e políticas locais, os funcionários nacionais de saúde muitas vezes trataram a resistência social como um problema de comunicação numa população que precisava ser educada, em vez de refletir sobre a estrutura da própria intervenção. As implicações dessas realidades são profundas para as nossas políticas de saúde hoje em dia. Em 2007, a Fundação Gates ressuscitou a campanha fracassada, prometendo erradicar a malária do mundo. Um ano antes, a Organização Mundial da Saúde aprovou mais uma vez a dedetização de casas como etapa propícia à erradicação da malária. Como Cueto (2007) observa, mosquiteiros tratados com piretroide e produtos farmacêuticos tornaram-se as soluções técnicas de uma supostamente "nova era", a meta da erradicação da malária ressuscitada agora, quatro décadas depois que seu fracasso original foi anunciado em 1969 (ver Bleakley, 2009).

O fato é que as abordagens do tipo da "bala mágica" são cada vez mais a norma em saúde global - isto é, a entrega de tecnologias de saúde (geralmente novas drogas ou aparelhos) dirigidas a uma doença específica apesar da miríade de fatores societários, políticos e econômicos que influenciam a saúde. Baseado em meu estudo da resposta terapêutica brasileira à AIDS, este artigo explora os limites da abordagem solução-instantânea-técnica-vertical em saúde global e a viabilidade de iniciativas "centradas nas pessoas". Nós precisamos de estruturas analíticas e capacidades institucionais que avancem além da repetição da história e enfoquem pessoas: envolvimentos na base que tratem as políticas de controle $e$ de não intervenção, a fragmentação de esforços, a presença da heterogeneidade, o pessoal e o interpessoal, a inventividade das pessoas.

É hora de atribuir às pessoas que estudamos e descrevemos os tipos de complexidades que reconhecemos em nós mesmos, e de trazer essas complexidades ao cenário da saúde global. Descrições populares e políticas tendem a mostrar as pessoas como vítimas indefesas, completamente condicionadas pelo meio ambiente, pela história e pelo poder, ou como miraculosos sobreviventes que dão testemunho do sucesso da ajuda externa. Os detalhes são omitidos. Instituições falidas, divergências que se aprofundam e economias 
políticas mais amplas nas quais essas vidas se desenrolam parecem periféricas tanto à análise quanto ao ativismo. Nas ciências sociais, métodos como os ensaios randomizados são aclamados como "balas mágicas" na busca de evidência científica e como "chaves" para desvendar os mistérios de saúde e desenvolvimento. As pessoas são enquadradas em moldes preconcebidos. As populações humanas que constituem os objetos de estudos de saúde e desenvolvimento não são, entretanto, apenas fonte de problemas. Seu conhecimento prático pode muito bem conter soluções eficazes - conhecimento experiencial que é rapidamente desqualificado por patrocinadores de soluções técnicas em busca de resultados rápidos.

Os esforços cotidianos das pessoas e as dinâmicas interpessoais transcendem abordagens experimentais de curto prazo e exigem escuta e compromissos de longo prazo (Biehl, 2005; Scheper-Hughes, 2008; Tsing, 2004; Whitmarsh, 2008). A tarefa da antropologia no campo da saúde global é produzir diferentes tipos de evidência, abordando desafios ousados como a farmaceuticalização da assistência médica e questões cruciais como o que acontece com a cidadania quando a política se reduz à sobrevivência - com um profundo e dinâmico sentido de mundos locais (Petryna; Lakoff; Kleinman, 2006). O antropólogo demarca territórios não mapeados e acompanha as pessoas que se movem através deles. No campo, o inesperado acontece diariamente e novas causalidades entram em jogo. Uma receptividade ao que é surpreendente e o uso de categorias que são importantes na experiência humana podem tornar nossa ciência mais realista e possivelmente melhor.

\section{"Minha política é ver as coisas humanamente"}

Eu conheci Evangivaldo em 1997. Sem teto e com escabiose contagiosa, Evangivaldo fora enviado do pavilhão de AIDS do hospital estadual para a Caasah - uma das 500 "casas de apoio" brasileiras que ajudavam doentes de AIDS pobres a navegar no precário sistema de saúde. Os antirretrovirais estavam se tornando disponíveis, mas as instituições públicas mal funcionavam e o governo cada vez mais terceirizava a assistência para os serviços comunitários. "Preciso conversar, falar todas as verdades", eu me lembro de ouvir Evangivaldo pela porta do quarto onde ele estava de quarentena: "Tenho essa triste psicose na minha cabeça." 
Os pais de Evangivaldo morreram quando ele era jovem e ele foi criado por um tio. Ainda adolescente, ele se mudou para Salvador no início da década de 1980. "Eu carreguei muitos sacos de farinha nas costas para comprar meu primeiro par de sandálias", ele disse. "Mais tarde, eu levei prostitutas aos navios atracados aqui." Ele estava lutando por pertencimento: "Tem gente aqui que acha que é superior por causa da cor da pele, ou porque tem um doutor que gosta deles, ou porque estão

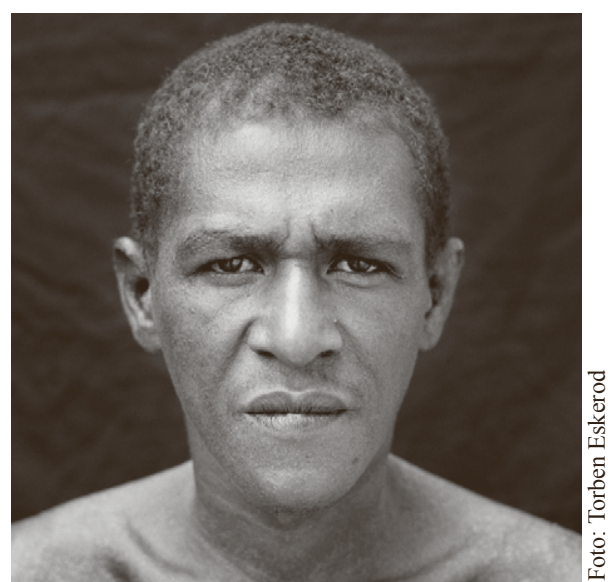

Figura 2. Evangivaldo, 1997. mais bem de saúde."

A Caasah (Casa de Apoio e Assistência ao Portador do Vírus HIV/AIDS) foi fundada em 1992, quando um grupo de doentes de AIDS desabrigados ocupou um hospital abandonado que tinha sido da Cruz Vermelha. Em pouco tempo, a Caasah tornou-se uma organização não governamental (ONG) e começou a receber auxílio de um financiamento do Banco Mundial distribuído pelo governo brasileiro. Em meados da década de 1990 os doentes desordeiros tinham sido despejados da Caasah e um grupo menor se submeteu a um intenso programa de ressocialização conduzido por psicólogos e enfermeiros.

"Com o tempo, nós os domesticamos", recordou Celeste Gomes, diretora da Caasah. "Eles não tinham conhecimento nenhum. Nós mostramos a eles a importância de usar a medicação. Agora eles têm consciência disso e lutam por suas vidas."

Evangivaldo foi um dos poucos que teve essa chance. Ele e seus companheiros "cidadãos da AIDS" (como muitos na Caasah gostavam de se chamar) sabiam muito bem que as desigualdades do poder, desde a destituição econômica até a discriminação racial, determinavam quem tinha acesso a quais serviços. Eles tinham de assumir uma nova identidade de paciente, e essa habilidade recém-aprendida de "acumular" saúde na Caasah também era um empreendimento altamente competitivo. "Alguma vez você já viu um doente de AIDS aqui desejar o bem-estar do outro?" Evangivaldo me perguntou. De fato, os residentes ficavam constantemente apontando as falhas uns dos outros 
e comparando condições clínicas. O mau comportamento ou a indisposição do outro eram a medida da sua própria melhora de saúde. O dinheiro também estava em jogo. A Caasah estava facilitando pedidos de auxílio-doença para AIDS e a prioridade era para os residentes que apresentavam mudança. Cada um cuidava apenas de si. Como me disse um doente: "Morreu um Luis e apareceu outro. Eu me acostumei com a medicação. A medicação agora sou eu. Hoje a gente só morre de AIDS se quiser." Mas Evangivaldo pensava diferente: "Minha politica é ver as coisas humanamente. Quem for mais forte agora precisa ajudar o mais fraco." Depois de um ano na Caasah, a Fátima entrou na vida dele, ele disse. "Quando fui melhorando eu disse a ela: 'Igual a você, eu não tenho família. Eu não tenho ninguém por mim. Vamos viver juntos.' E ela disse 'sim'."

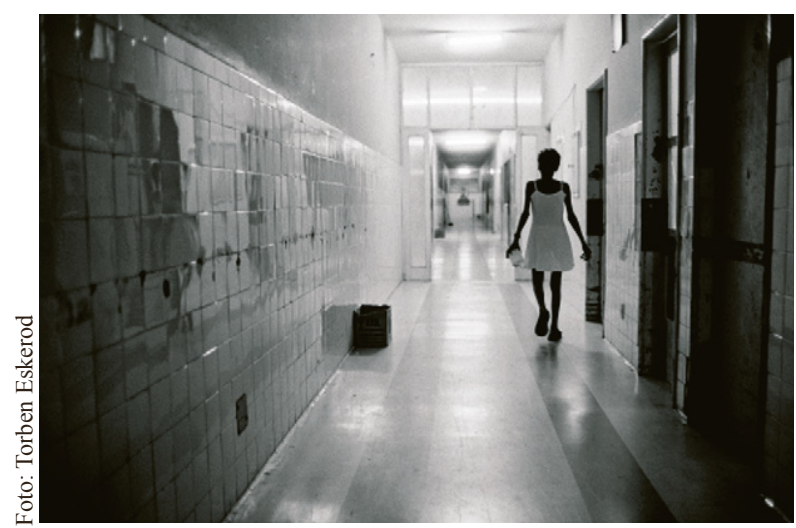

Figura 3. Caasah, 1995.

\section{Entrementes e além do biopoder}

Não existe atalho para compreender como uma vida tecnologicamente prolongada é alcançada - seja no Brasil, ou no número crescente de outros países pobres onde a AIDS está finalmente sendo tratada através de uma série de iniciativas públicas e privadas sem precedentes. Mais de 25 milhões de 
pessoas morreram de AIDS até hoje e calcula-se que 33 milhões estão vivendo com HIV em todo o mundo, cerca de dois terços delas na África subsaariana. Uns dez milhões de pessoas estão precisando de terapia antirretroviral. A batalha por acesso tem sido dura e quase quatro milhões estão agora em tratamento em países de baixa e média renda.

Os lançamentos dessa política global de tratamento da AIDS certamente abrem a porta de acesso ao medicamento, mas também exemplificam as deficiências da abordagem do tipo "bala mágica" à assistência de saúde. As drogas são auxiliares no tratamento completo da doença. Isoladamente, nem dinheiro nem drogas nem projetos-piloto sofisticados garantem o sucesso. A cura, afinal, é um conceito multifacetado e "curar" não é mais sinônimo de "tratamento" do que "tratamento" é de "drogas". As estratégias estatísticas e a motivação do lucro pairam acima disso, geralmente deixando de ver as redes interpessoais que ligam doentes, médicos e governos, que são especialmente importantes em contextos com poucos recursos, onde as infraestruturas clínicas não estão melhorando. As mortes por AIDS e infecções por HIV continuam crescendo entre os destituídos. Calcula-se em três milhões o número de novas pessoas infectadas anualmente. Para elas, HIV/AIDS é uma tragédia entre muitas outras.

Essas realidades não são redutíveis às teorias que trazemos para o campo. Inúmeros antropólogos têm usado as formulações de biopoder de Michel Foucault $(1990,2007)$ - estudando como a vida natural foi tomada como objeto da política moderna - para acessar as montagens de tecnologia, remédios e governança que estão surgindo, especialmente diante do HIV/AIDS (Comaroff, 2007; Fassin, 2007; Nguyen, 2005; Robins, 2006). Ainda assim essa influente lógica biopolítica - "fazendo viver e deixando morrer" - merece um exame mais profundo, para evitar que seja vista em termos de formas transcendentes de poder, povos homogêneos, ou populações excessivamente normalizadas (Foucault, 1990, 2007). Como Ian Hacking (1999, p. 162, tradução minha) reconheceu, em seu ensaio sobre como novos tipos de pessoas podem ser "criados" por diagnóstico médico: "Meu interesse é filosófico e abstrato [...] e reflito muito pouco sobre as dinâmicas comuns da interação humana."

O que está além do biopoder? Atravessando mundos de risco e escassez, limitadas sem serem totalmente sobredeterminadas, as pessoas criam pequenos e passageiros espaços, através e além de classificações e aparatos de governança e controle, nos quais podem desempenhar um tipo de bricolagem de 
vida com as escolhas e os materiais limitados que têm à sua disposição (inclusive de serem sujeitos de direitos e de receberem tratamentos farmacêuticos disponibilizados por atores estatais e não estatais). Estudiosos e criadores de políticas públicas são desafiados a respeitar e tornar publicamente inteligíveis, sem reducionismo, a angústia, a incerteza, a paixão pelo possível e as labutas que pessoas como Evangivaldo, em meio a intervenções para salvar a vida, são deixadas para resolver por conta própria e, muito frequentemente, em detrimento de outros.

Durante mais de dez anos, eu colhi relatos da vida dentro e fora da Caasah. Retornando várias vezes ao campo, começa-se a entender o que acontece no intervalo - e gosto de considerar este trabalho como um estudo do intervalo - os eventos e práticas que possibilitam mudança social e política mais ampla, junto com os que debilitam sociedades e indivíduos, condenandoos à estase e à inflexibilidade. Nesses retornos, o emaranhado de detalhes vem à tona. Testemunhamos como as políticas se desenrolam ao longo do tempo - e a literalidade do vir a ser, na medida em que os sobreviventes da AIDS passam da condição de pacientes para a condição de pessoas. Eu digo vir a ser, pois temos a responsabilidade de considerar a vida em termos tanto de limites como de encruzilhadas, onde as tecnologias, relações interpessoais e imaginação podem às vezes, e contra todas as chances, se expandir para futuros inesperados.

Evangivaldo, Torben e eu nos sentamos sob uma árvore no quintal e olhávamos os retratos dos moradores da Caasah que Torben tinha feito em 1997. Com uma simples cadeira e um pano preto contra um muro de tijolo, tínhamos improvisado um estúdio fotográfico. Torben fotografava cada pessoa e gravava suas histórias de vida. "Este trabalho foi importante para mim, ele marcou minha história", Evangivaldo disse. Celeste, a diretora, se juntou a nós: "Você realmente captou a pessoa", disse ela a Torben com um suspiro. Com certa melancolia, Celeste admitiu que "no trabalho do dia a dia realmente a gente não via isso... fingíamos que sabíamos quem eles eram”.

Quanto a Evangivaldo: "Sei que isso é um tipo de trabalho científico para as pessoas verem o que nós passamos aqui no Brasil, mas eu também quero mostrar para o meu médico e as enfermeiras. Quero que eles vejam como eu mudei." Evangivaldo nos mostrou a receita do antidepressivo de que ele também precisava, mas não podia comprar. "Já estamos devendo 75 reais na farmácia", ele disse - aquilo era a metade de sua pensão por invalidez. "Acordo 
às 4 h da manhã e ando duas horas de bicicleta para chegar ao centro da cidade. Vou de porta em porta procurando um trabalho. Tem dias que eu não consigo o dinheiro que preciso e fico apavorado. Eu me escondo num canto e choro. Depois não sei mais onde estou." Assim mesmo, ele encontrava maneiras de superar o sentimento de sufoco. "Eu digo: 'Concentre, Evangivaldo, concentre, você vai achar sua bicicleta e o caminho de casa.' E sabe por que eu consigo fazer isso? Porque a minha Juliana tá me esperando."

Com a disponibilidade das terapias antirretrovirais, residentes saudáveis como Evangivaldo e Fátima tinham sido avisados que deveriam se mudar da Caasah. E, no ano passado, a própria Caasah mudou para um novo prédio alugado pelo estado. Ela tinha sido reorganizada como casa de recuperação de curto prazo para doentes enviados pelos pavilhões de AIDS dos hospitais e como abrigo para órfãos com HIV. O mais preocupante é que não havia nenhum esforço sistemático para acompanhar os doentes e seus tratamentos depois de deixarem a casa.

Hoje as terapias de AIDS estão incrustadas em paisagens de miséria, e centenas de serviços comunitários ajudaram a tornar a AIDS uma doença crônica também entre os mais pobres no Brasil e fora dele. Isso não é uma forma de controle biopolítico de "cima para baixo". O governo não está usando terapias de AIDS e serviços comunitários como "técnicas [...] para governar populações e dominar corpos individuais" - como o antropólogo Vinh-Kim Nguyen (2005, p. 126, tradução minha) enquadrou as políticas de globalismo antirretroviral. Como estou afirmando à luz da Caasah, a questão da responsabilidade tem sido deslocada das instituições de governo, e as populações de AIDS pobres tomam forma, ainda que temporariamente, através de compromissos específicos com o que se torna farmaceuticamente disponível. O jogo político aqui é o da autoidentificação. Comunidades locais, muitas vezes temporárias e frágeis, e os desejos e dinâmicas interpessoais são fundamentais para as chances de vida, que se desdobram atreladas a um estado que está farmaceuticamente presente (através de mercados), mas em geral institucionalmente ausente.

À margem, as preocupações tanto institucionais quanto farmacológicas em torno do tratamento da AIDS passam por mudanças consideráveis (ver Reynolds Whyte et al., 2006). E os próprios sobreviventes de AIDS pobres vivem em um estado de fluxo, ao mesmo tempo admitindo e ocultando sua condição enquanto participam de economias de salvação locais e articulam 
singularidades públicas. Contra o pano de fundo de uma infraestrutura de assistência médica limitada e morte econômica, e através de múltiplos circuitos de assistência, a subjetividade individual é reconcebida como um desejo de viver.

O filósofo Giorgio Agamben (1998, p. 4) também informou significativamente os debates biopolíticos contemporâneos com sua evocação do homo sacer e a asserção de que "a vida exposta à morte" é o elemento original das democracias ocidentais. Essa "vida nua" aparece em Agamben (1999) como um tipo de destino histórico-ontológico - "algo pressuposto como não relacional" e "dessubjetivado". Vários antropólogos criticaram o modo apocalíptico de Agamben tratar a condição humana contemporânea e a desumanização que acompanha essa melancólica (ainda que comovente) maneira de pensar (Das; Poole, 2004; Rabinow; Rose, 2006). Seja em abandono social, dependência, ou desabrigo, a vida que não tem mais nenhum valor para a sociedade não é sinônimo de vida que não tem mais nenhum valor para a pessoa que a vive (Biehl, 2005; Bourgois; Schonberg, 2009; Garcia, 2008). A linguagem e o desejo continuam com significado mesmo em circunstâncias de profunda abjeção (Biehl; Moran-Thomas, 2009). Essas realidades tão difíceis e multifacetadas e a natureza fundamentalmente ambígua das pessoas que as vivem dão aos antropólogos a oportunidade de desenvolver uma crítica humana, e não abstratamente filosófica, das máquinas nada excepcionais de morte social e (auto)consumo nas quais as pessoas são enredadas. Contra todas as probabilidades, as pessoas continuam buscando reconhecimento social e maneiras de resistir, às vezes retrabalhando e sublimando aflições e constrangimentos.

Reconhecer as percepções e capacidades humanas alternativas que brotam da abjeção também nos obriga a investigar como elas podem ser parte inseparável dos esforços necessários para redirecionar políticas de assistência. Assim a necessidade de uma textura subjetiva também levanta questões antropológicas mais amplas sobre o potencial inigualável da etnografia para trazer a vida privada da mente para as conversas sobre a saúde pública e a política. Mais do que ilustrar etnograficamente as silhuetas da teoria biopolítica, as novas maneiras de pensar sobre o pertencimento e a subjetividade nos obrigam, ao invés disso, a considerar os próprios termos desse quadro teórico (Fischer, 2009; Rancière, 2004).

Gilles Deleuze (2006), que não compartilhava a confiança de Foucault na força determinante dos arranjos de poder, é útil aqui. Segundo Deleuze, o desejo, através de invenções, fugas e sublimações que ele motiva, está 
constantemente desfazendo - ou pelo menos abrindo - formas de subjetividade e territorializações de poder. Seguindo o raciocínio de Deleuze e Guattari (1986) em Kafka: por uma literatura menor, mesmo o conceito de montagem (assemblage), adotado recentemente por Aihwa Ong e Stephen Collier para se referir às configurações globais emergentes - como "tecnociência, circuitos de troca lícita e ilícita, sistemas de administração ou governança, e regimes de ética ou valores" (Collier; Ong, 2005, p. 4, tradução minha) - teria desejo em seu cerne. Para Deleuze e Guattari (1986, p. 86), montagens são inter-relações contingentes e mutáveis entre "segmentos" - instituições, poderes, práticas, desejos - que constantemente constroem, entrincheiram e desagregam simultaneamente seus próprios constrangimentos e opressões. Essa ênfase no desejo e as maneiras - modestas, marginais, menores - como ele irrompe em campos sociais aparentemente rígidos, servindo de motor ao vir a ser, está no centro das divergências de Deleuze com Foucault, cuja arqueologia do sujeito rastreia as maneiras em que este é constituído e confinado por categorias de discursos de especialistas, naquilo que, mais uma vez, poderia ser visto como um movimento vertical, de cima a baixo (Biehl; Locke, 2010).

Os avanços epistemológicos não pertencem apenas a especialistas e analistas. As experiências cumulativas da "imprevisibilidade dos efeitos sociais e políticos de invenções tecnológicas" - carregadas por pessoas que navegam nos emaranhados contemporâneos de poder e conhecimento - representam também rupturas epistemológicas que exigem reconhecimento antropológico (Canguilheim, 1998, p. 318, tradução minha). O compromisso a longo prazo com as pessoas é mesmo um antídoto vital para aquilo que o economista Albert Hirschman (1971) identifica como "a teorização compulsiva e insensata". Em nossa cultura, a solução teórica instantânea tomou um lugar ao lado da solução técnica instantânea. Para Hirschman, como para o antropólogo, as pessoas vêm em primeiro lugar. Esse respeito pelas pessoas, essa atenção a como as políticas são montadas - como elas se implantam institucionalmente e se ajustam a relações sociais desiguais - faz uma enorme diferença no tipo de conhecimento que produzimos. Como escreve Hirschman (1971, p. 338, tradução minha), "em todas essas questões eu sugeriria um pouco mais de reverência pela vida, um pouco menos de tolhimento às possibilidades futuras, um pouco mais de tolerância com o inesperado - e um pouco menos de otimismo cego".

$\mathrm{O}$ antropólogo, fazendo valer seus direitos à microanálise, torna visíveis os campos que as pessoas, cheias de ambiguidade, inventam e que regem 
suas vidas. Tais campos de ação e significância - vazando de todos os lados - são mediados por poder e conhecimento e são também animados por reivindicações de direitos básicos $e$ desejos, como Evangivaldo afirma. Não basta simplesmente observar que existem complicadas novas configurações de segmentos globais, políticos, técnicos, biológicos (etc.) ou que elas são temporariamente a norma. Precisamos ficar atentos às maneiras como essas configurações são constantemente construídas, desfeitas e refeitas pelo desejo e o devir de pessoas reais - vivendo no caos, no desespero e na aspiração, da vida em circunstâncias idiossincráticas. A escolha que devemos fazer não é necessariamente entre montagens basicamente globais (Collier; Ong, 2005) e "fragmentos" principalmente locais de um "mundo despedaçado" (Geertz, 2000). No horizonte dos dramas locais, no desenrolar de cada evento, nos altos, baixos e entornos de cada vida individual, podemos ver o reflexo de sistemas maiores em construção (ou desconstrução). E ao tornar públicos esses campos singulares - sempre à beira de desaparecer - o antropólogo ainda permite que processos estruturais e idiossincrasias institucionais mais amplos se tornem visíveis e seu verdadeiro impacto conhecido.

\section{Desigualdades persistentes e a aura cientifica de fingir não saber}

Em 2000, as autoridades de saúde da Bahia anunciaram que um patamar fora atingido e que a incidência de AIDS estava em declínio, em alinhamento ostensivo com as estatísticas mais recentes apontando para o sucesso da política de controle do país. Mas a realidade da AIDS que vi nas ruas de Salvador contradiziam esse perfil, e uma preocupação central de minha etnografia tinha sido expor os limites da vigilância e gerar alguma forma de responsabilidade e visibilidade para a epidemia oculta de AIDS experimentada pelos mais vulneráveis e marginalizados.

Enquanto observava a vida literalmente em construção na Caasah, eu também tomava nota do trabalho de Dona Conceição, uma enfermeira, que fornecia refeições e algum tipo de cuidado para uma centena de doentes de AIDS desabrigados, envolvidos em economias informais e sustentando filhos. "A assistência médica nunca atende a demanda, e a sociedade civil os abandonou", Dona Conceição me disse. "Eu tento aliviar um pouco as coisas. Estou ligada a eles em espírito.” 


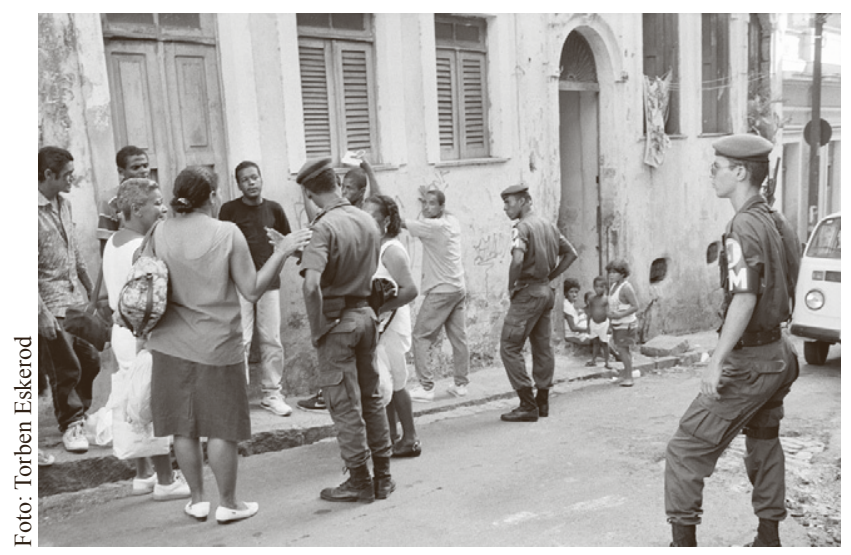

Figura 4. Dona Conceição e seus "pacientes de rua".

Eu me encontrei com funcionários do serviço de vigilância epidemiológica do estado e lhes pedi que verificassem se alguns dos moradores de rua que declaravam ser tratados no serviço médico de AIDS do estado estavam registrados no seu banco de dados. Não havia nenhum registro desses doentes. No entanto, do meu ponto de vista, eles estavam morrendo uma morte muito pública - um destino do qual Evangivaldo e outros doentes-cidadãos tentavam escapar através de esforços extraordinários.

É interessante notar que o registro computadorizado brasileiro de doentes em terapia antirretroviral inclui dados sobre combinações de tratamento, dosagens e contagens de $\mathrm{CD} 4$, e mesmo assim não inclui indicadores sociais específicos. Sem saber onde esses doentes vivem, não podemos avaliar a cobertura da política nacional; sem conhecer os níveis de educação ou renda, a dinâmica de classe que funciona no acesso ao tratamento permanece desconhecida; sem uma noção das redes sociais dessa nova população médica, não conhecemos os padrões de adesão e como o acesso aos medicamentos se traduz em melhor saúde. O fato é que no fundo, a política de tratamento da AIDS reproduz as linhas discriminatórias de raça e pobreza e vemos resultados desiguais para os doentes, bem como estigma e discriminação incessantes, mesmo da parte de profissionais da saúde. Em 2005, um levantamento sobre a mortalidade no estado de São Paulo revelou que a AIDS é duas vezes mais fatal entre negros do que entre brancos (Brito, 2005). 
Essas tendências mostram a necessidade de avaliações mais aprofundadas de programas. Ainda assim, o campo da saúde pública global, incluindo AIDS, é dominado pela análise econométrica com suas altas pretensões à superioridade estatística e epistêmica (Heckman; Vytlacil, 2007) mas com generalizabilidade distorcida e prazo de validade curto. Como observa o economista Angus Deaton (2009), em contextos como o do Brasil, uma ciência baseada em análises randomizadas (a "randomização nos trópicos") tem pouca chance de lançar luz sobre os elementos-chave do desenvolvimento, pois tais esforços não permitem perceber por que certos programas funcionam ou outros não. Excluindo a observação e deixando na sombra tudo que foge das condições ideais, "as soluções técnicas instantâneas falham, pois comprometem nossas tentativas de aprender com o momento" (Deaton, 2009, p. 47, tradução minha). As perguntas eminentemente humanas "por que aqui, por que eu, por que agora?" - tão cruciais para os antropólogos - muitas vezes são esquecidas.

Para entender como as vítimas de AIDS desaparecem dos registros públicos, eu colaborei com epidemiologistas locais. Nós juntamos os atestados de óbito de todos os pacientes de AIDS no serviço de AIDS do estado durante mais de seis anos. Descobrimos que mais da metade morreu na primeira hospitalização, sugerindo que a maioria dessas pessoas só tinha acesso aos serviços hospitalares já à beira da morte. Descobrimos também que apenas $26 \%$ desses casos de AIDS eram de fato registrados pelo serviço de vigilância. Ficamos intrigados. O que é que tornava alguns desses casos de AIDS oficialmente visíveis e a maioria não? Comparados aos doentes que morreram durante a primeira hospitalização, os doentes que morreram durante uma hospitalização posterior tiveram dois terços mais chances de ser registrados. Além disso, os homens que se identificaram como bissexuais ou homossexuais tiveram $50 \%$ menos chances de ser cadastrados do que os que informaram heterossexualidade.

Esses vácuos e vieses não eram apenas resultado de vigilância precária que pudesse ser tratada com uma simples solução técnica. O problema estava enraizado em três fatores: primeiro, a lógica operacional de um sistema de assistência médica que circunscreve a prestação de serviços a cerca de $30 \%$ da demanda - aqueles doentes que buscam de maneira autônoma um tratamento continuado, lutando por seus lugares em serviços superlotados e com poucos recursos; segundo, uma poderosa soberania médica que pode negligenciar doentes considerados como indignos; e terceiro, as maneiras problemáticas 
como as pessoas marginalizadas que vivem com HIV/AIDS respondem a suas doenças tendo em vista o sistema de assistência fragmentado e as economias ilícitas com as quais elas se envolvem. "Quando chegam, já estão morrendo", a assistente social me disse. "Eles nunca se curam. Sem ter onde morar, como podem seguir o tratamento? Deve haver milhares como eles." Não existem registros indicando o empenho dessas pessoas e as complexas interações sociais e econômicas que exacerbam infecções e depressões imunológicas continuam inexplicadas.

Meus colegas e eu escrevemos um relatório dirigido à Secretaria de Saúde da Bahia informando-lhes sobre a existência dessa epidemia oculta de AIDS. Mais tarde eu soube que o relatório foi arquivado. No interior desses campos de força locais, ao mesmo tempo em que a inovadora política brasileira de tratamento de AIDS ia ganhando vida e atraindo atenção internacional, configuravam-se ilhas de assistência médica dentro de uma política estatal calcada na triagem, e a morte social continuou seu curso.

\section{Da epidemia coletiva a uma política de sobrevivência altamente privatizada}

Quando retornei a Salvador em 2001, trabalhei com uns 30 doentes sem teto que ainda eram cuidados por Dona Conceição. Agora eles estavam morando numa plataforma de concreto adjacente ao principal estádio de futebol da cidade. Muitos pareciam subnutridos, tinham lesões de pele e se queixavam de sintomas semelhantes aos da gripe. Mas então, como disse Carisvaldo, "tocamos a vida em frente de qualquer jeito". Muitos disseram que tinham começado a pegar antirretrovirais de graça nos hospitais, mas que tinham parado de usar. Segundo Roberto, "Só a medicação não resolve nada". Seu amigo Luis disse que não acreditava na eficácia das drogas: "Meu remédio é comida, é feijão na barriga." Uma cultura de aderência estava longe daqui.

O que presenciei ali revela muito sobre a evolução trágica da epidemia de AIDS entre as populações marginalizadas. Uma manhã, duas meninas, de 13 e 15 anos, tinham se juntado à "tribo da rua". Elas tinham acabado de fugir da prostituição forçada. Dois doentes de AIDS desabrigados as encontraram vagando sem rumo e as trouxeram para o estádio de futebol, onde elas foram, mais uma vez, forçadas a fazer sexo. "Quero ir para casa", me disse uma menina, tremendo. Eu estava conversando com elas, quando chegaram funcionários do serviço de atendimento ao menor e disseram que levariam as meninas 
de volta à cidade delas. Quando o carro da polícia ia saindo, os varredores de rua que tinham ficado ali o tempo todo disseram em tom de gracejo para as pessoas remanescentes: "A carne fresca de vocês foi embora."

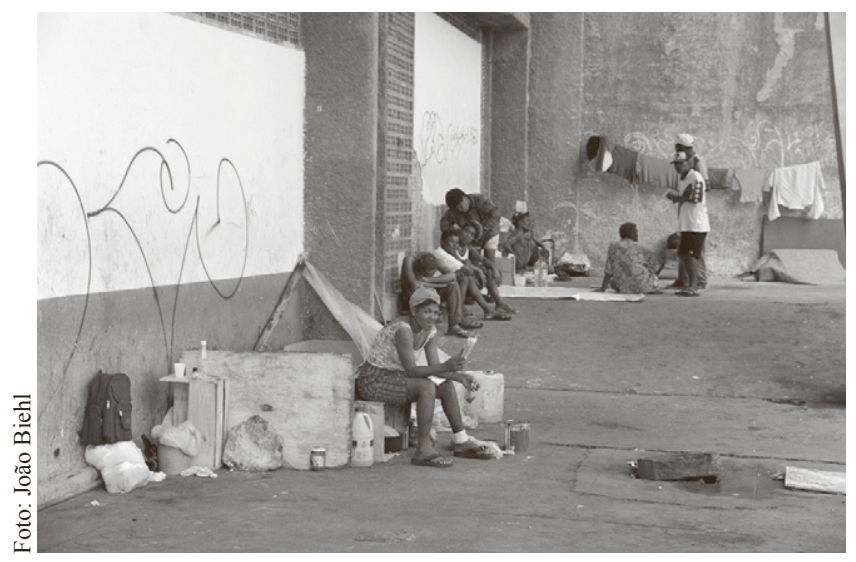

Figura 5. Moradores de rua.

No final daquela semana fui a Brasília e, na capital do país, tive um encontro com o Dr. Paulo Teixeira, então coordenador do Programa Nacional de AIDS. "O sucesso da política brasileira de AIDS é uma consequência do ativismo de comunidades afetadas, profissionais da saúde e governo", ele me disse. Dois anos mais tarde, eu ouviria uma explicação semelhante de Fernando Henrique Cardoso, ex-presidente do Brasil: "A resposta do Brasil à AIDS é um microcosmo de uma nova parceria entre o estado e a sociedade", ele me disse. Cardoso exibia a política de AIDS como evidência do suposto sucesso de sua agenda de reformas - um Estado aberto à sociedade civil, ativista em relação ao mercado e que adotava parcerias para a transferência de tecnologia. "Todo o trabalho de ONGs, a legislação sobre o tratamento médico, a luta por preço de medicamentos são novas formas de governamentalidade em ação... engendrando alguma outra coisa, produzindo um mundo novo."1

1 Todas as citações são tiradas de entrevistas realizadas por mim (ver Biehl, 2007 para mais detalhes).

Horizontes Antropológicos, Porto Alegre, ano 17, n. 35, p. 257-296, jan./jun. 2011 
A política de AIDS emergiu sobre o pano de fundo da neoliberalização, e os políticos envolvidos com ela estavam articulando conscientemente um conceito de sociedade de mercado. Para Cardoso, os cidadãos são consumidores que têm "interesses" em vez de "necessidades". Ou, nas palavras do economista e ex-ministro da saúde José Serra, "o governo acaba respondendo às pressões da sociedade. Se a tuberculose tivesse um quinto da mobilização social que tem a AIDS, o problema seria resolvido. Então, é um problema da própria sociedade." Nessa perspectiva, o governo não busca áreas de carência ou problemas específicos para cuidar - esse trabalho cabe aos grupos de interesse mobilizados. Essas ações públicas são consideradas "mais abrangentes e eficazes do que a ação do Estado" (palavras de Cardoso). Na prática, o ativismo reforçou a capacidade administrativa do Estado reformador.

$\mathrm{Na}$ minha entrevista com Dr. Teixeira mencionei a realidade da AIDS que eu acabara de observar nas ruas de Salvador. "É um retrato do Brasil", ele disse. "Não estou feliz com o trabalho que vem sendo feito com a AIDS e as populações. Temos que identificar uma estratégia que funcione." Dr. Teixeira deixou clara a posição do Estado de basicamente relegar a assistência às organizações comunitárias e acrescentou: "Trabalhar com essas pessoas não é o mesmo que trabalhar com a elite em São Paulo, mas também é possível ser eficaz. Se eu conseguir de 20 a 30\% de eficácia com essas pessoas já é um passo muito importante." Ouvindo-o, eu me lembrei dos 26\% de casos de AIDS registrados no serviço de vigilância baiano, das maneiras como o Estado local circunscreve a população para atendimento. "Nós temos que melhorar isto", Dr. Teixeira repetiu.

Mas as ONGs de AIDS que deveriam ter assumido o atendimento "perderam o idealismo e a paixão há muito tempo", o ativista Gerson Winkler me contou com amargura. Winkler vive com HIV/AIDS há mais de duas décadas e é um dos maiores críticos da política: "Agora é tudo um jogo de faz de conta", ele disse: "Eu seleciono uma clientela e finjo que faço um projeto, você finge que está vendo, o governo finge que está monitorando e todos nós fingimos que os resultados são verdadeiros. É uma farsa pensar que as ONGs podem executar os serviços do Estado." Questionado sobre essa crítica, Dr. Teixeira respondeu: "Houve coisas ruins no processo? Sim, mas sem terceirizar o atendimento, tampouco teria havido avanços. A evolução não acontece em direção única - vai para frente e para trás. Esperamos que sejam dois passos para frente e um para trás." 
Winkler lamentou que nessa dança, a política de AIDS tenha se tornado cada vez mais atomizada e que os doentes pobres tenham sido reduzidos a catadores de atendimento. "O estigma é constante", ele continuou. "A maioria dos doentes pobres nunca teve um emprego formal. É muito difícil ajudá-los a desenvolver uma mentalidade de trabalho e colocá-los no mercado." Em outras palavras, na história que estou lhes contando, vemos um movimento da epidemia coletiva para uma do-

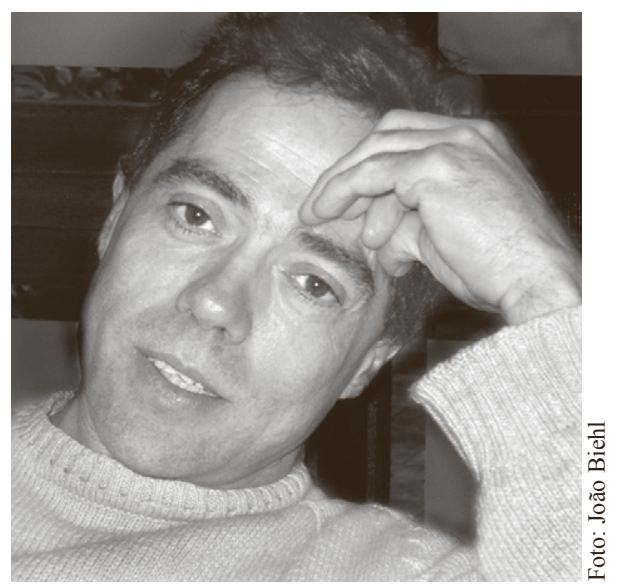

Figura 6. Gerson, 2005. ença personalizada; da saúde pública para a farmaceuticalização do atendimento à saúde; do afastamento governamental para a industrialização do setor não governamental e para uma política de sobrevivência altamente privatizada.

A trajetória de Evangivaldo, como a de muitos outros, mostra quão empoderador pode ser o acesso farmacêutico, mas também quanto esforço adicional é necessário para transformar medicamentos que são "acessíveis" em medicamentos que são eficazes na vida cotidiana dos doentes pobres. Uma campanha vertical contra a doença, de cima para baixo, embora valiosa, deixa de considerar as realidades sociais que coconstroem resultados de saúde (Easterly 2006, 2008). As políticas de saúde precisam ser dirigidas às pessoas, não simplesmente à doença.

O mais proeminente proponente de uma abordagem inovadora que combine a intervenção tecnológica vertical com o foco horizontal de fazer funcionar os sistemas de saúde, o norte-americano Dr. Paul Farmer (2001, 2003), é antropólogo. Ele e seus colegas da Partners in Health (Parceiros em Saúde) trabalham com comunidades locais no Haiti, em Boston, no Peru, e agora em Ruanda. As clínicas locais tornam-se um nexo de atendimento, integrando tratamento e atividades de prevenção de HIV/AIDS, ao mesmo tempo em que também tentam tratar as coinfecções e os novos problemas de saúde que os doentes de AIDS enfrentam quando envelhecem. Dar atenção às trajetórias individuais e acompanhar os pacientes ao longo da progressão e do tratamento 
da doença (o trabalho de cuidadores pagos chamados accompagneteurs) é considerado tão importante quanto enfrentar os fatores econômicos e sociais que afetam suas famílias e atenuar a carência de infraestruturas clínicas. $\mathrm{Na}$ Ruanda rural, por exemplo, cada doente que recebe drogas antirretrovirais também recebe alimento para cinco pessoas. Embora esse modelo biossocial possa ser rejeitado pelas ortodoxias de saúde pública com a justificativa de não ser "sustentável" ou não ter bom "custo-benefício", ainda assim ele expande o campo de possibilidades e ajuda a formar novos padrões de atendimento e intervenção (Farmer, 2008).

A vida real tem de ser colocada de volta na esfera de competência das políticas de AIDS. Isso exige ir onde as pessoas estão. Os doentes miseráveis, sem voz política, têm sido ignorados, não necessariamente por ignorância ou falta de capacidade do governo. Nos lugares onde houve triagem, testes e atendimento efetivos de HIV - nas maternidades brasileiras, por exemplo - a infecção foi reduzida. Por que não, então, procurar outros grupos vulneráveis e discutir intervenções com eles? Precisamos inovar e encontrar maneiras de testar, tratar e manter atendimento disponível aos grupos que escapam de categorias embora sejam os que mais sofrem com a epidemia.

\section{Abordando o emaranhado de gente-doença-política e a dinâmica de mercado}

Enquanto isso, a abordagem da "bala mágica", concentrada no gerenciamento da cadeia de fornecimento e distribuição de medicamentos, se estende muito além do lançamento de antirretrovirais. Muitas doenças tropicais também foram objeto de abordagens do tipo generalizante, entre elas a malária infantil, o "mal dos rios" (oncocercose) e infecções parasitárias. Mas, como nos lembram os historiadores do combate à sífilis e à malária, a erradicação é um alvo enganador (Brandt, 1985; Cueto, 2007). Assim como mudam o know-how médico, a dinâmica política internacional e as realidades sociais, os sistemas biológicos também estão em fluxo - bactérias ficam resistentes, surgem novas infecções. Um modelo mais complexo desse fluxo de gentedoença-política $e$ dinâmica de mercado é necessário - e isso exige parcerias e métodos inovadores.

No verão de 2008, Amy Moran-Thomas acompanhou de perto o trabalho de prevenção de malária e campanhas de desparasitação que agentes de saúde 
e médicos de ONGs faziam no norte de Gana. Mesmo assim, visitando as comunidades, ela viu que esses esforços muitas vezes eram ignorados - tratamentos não seguidos, filtros d'água para o verme da Guiné e mosquiteiros jogados num canto, sem uso. As campanhas educativas tentavam corrigir essa aparente negligência, mas o problema era mais profundo. Quando ela perguntava às pessoas quais eram suas maiores preocupações de saúde, elas falavam das léguas de caminhada para encontrar água limpa durante a estação da seca e da luta contra o diabetes num ambiente onde certa quantidade de comida barata importada era a única alternativa à fome (Moran-Thomas, 2009). Em outras palavras, as intervenções pareciam ignorar as complexas questões de saúde preventivas e ambientais mais centrais nas vidas dessas pessoas.

Consideremos o estudo muito citado de Michael Kremer e Edward Miguel (2007) sobre o combate a infecções parasitárias nas zonas rurais do Quênia. Miguel e Kremer descobriram que tratar os alunos de escola quenianos com vermífugos extremamente baratos aumentava sua frequência escolar em cerca de 10\%. Um editorial do New York Times chamou o estudo de "referência" (Kristof, 2007): só com um pouquinho de remédio barato, os países pobres poderiam aumentar significativamente seus índices de frequência escolar. Devido ao fácil acesso e impressionante sucesso do tratamento, muitos comentaristas achavam que as famílias que não tinham se beneficiado dele durante o estudo adotariam essa nova tecnologia com o maior prazer.

Mas Kremer e Miguel (2007) logo notaram uma surpreendente virada nos acontecimentos, ao acompanharem um grupo de famílias fora do estudo original após o término da experiência. Entre essas famílias, as que eram amigas de famílias no grupo de tratamento estavam menos propensas a tratar seus filhos do que as que eram amigas de famílias no grupo de controle. Elas estavam também menos propensas a considerar o remédio eficaz na melhoria da saúde. Se o vermífugo é a panaceia para anemia e evasão escolar, então por que famílias mais bem-informadas não estavam tratando seus filhos?

Mais uma vez, temos um caso em que as necessidades e relações interpessoais de gente da base eludem os estudos controlados. Permanece a questão desafiadora: como aprender a trazer comunidades locais ao planejamento e à implementação de intervenções factíveis, que não se contentam com o deslumbramento tecnológico. Considerando que o sucesso das políticas de saúde nacionais e internacionais é avaliado em grande medida em termos de fornecer e quantificar a entrega dos melhores medicamentos e das mais novas 
tecnologias, que espaço sobra para o desenvolvimento de soluções de baixa ou nenhuma tecnologia (tais como o fornecimento de água limpa) que poderiam acabar sendo mais sustentáveis e afinal mais humanísticas?

No Brasil, com os pacientes tirando proveito de novos medicamentos antirretrovirais, o orçamento anual de HIV/AIDS aumentou para US\$ $562 \mathrm{mi}$ lhões em 2006. Apesar da capacidade de produção de genéricos do país, cerca de $80 \%$ dos medicamentos distribuídos são patenteados. "Estamos indo na direção do monopólio absoluto de medicamentos", disse-me Michel Lotrowska, um economista que trabalha para a ONG Médicos Sem Fronteira no Rio de Janeiro. "Temos de encontrar uma nova maneira de reduzir preços. Se não, em breve os médicos terão de dizer aos pacientes: 'Só posso lhe oferecer a primeira linha de tratamento e, se você desenvolver resistência ao medicamento, você vai morrer'."

Recentemente, perguntei a um executivo da indústria farmacêutica como o setor privado e os governos com os quais sua companhia estava fazendo parceria na África consideravam esse problema. Para ele, o ponto crucial era a colaboração do doente. "Se esse lado for resolvido", ele disse, "então os tratamentos de segunda linha nem serão necessários". Além disso, ele disse, "o sistema de distribuição de medicamentos deve ser melhorado para garantir a consistência do tratamento". Por fim, ele me disse: "Precisamos investir em ciência básica e ter medicamentos melhores para começar." Patentes e complexas realidades técnicas e sociais que possam criar obstáculos à melhor prática de diagnóstico ou adesão não entram nessa conversa de saúde global.

Durante uma recente pesquisa em Salvador, eu soube que formadores de opinião médica estavam pedindo aos médicos que receitassem T-20 como tratamento de primeira linha ao invés de usá-lo como medicamento de resgate. O T-20 é um medicamento novo que ajuda muito os doentes com resistência a tratamentos anteriores, a um custo anual de US\$ 20 mil por paciente. Também ouvi dizer que alguns médicos começaram a receitar o medicamento de resgate Kaletra a partir de seu lançamento nos Estados Unidos, antes mesmo de ser registrado no Brasil. Esses médicos enviavam os pacientes a uma ONG de AIDS local e a advogados da defensoria pública que forçavam o Estado a fornecer o medicamento ainda não aprovado pela agência nacional de vigilância sanitária. Diante do onipresente marketing farmacêutico imiscuído na mobilização social, floresce a incoerência regulatória. Enquanto isso, os ativistas que 
contribuem para as políticas públicas têm de ficar inventando estratégias para manter em funcionamento os investimentos nacionais no tratamento de AIDS.

A Índia foi um país crucial na última década, usando com proveito o período de transição instituído pela Organização Mundial do Comércio para que os países-membros pudessem traduzir em lei a forte proteção de patentes. Durante esse período, a Índia especializou-se na fabricação de genéricos de medicamentos de HIV/AIDS patenteados, que tiveram grande importância na redução de preços no mundo e garantiram acesso a tratamento em países de poucos recursos. Mas, a partir de 2005, a fabricação de genéricos de drogas patenteadas foi terminantemente proibida. Isso não poderia ter vindo em hora pior, pois medicamentos patenteados, como Tenovir e Efavirenz, substituíram tratamentos de primeira linha preexistentes, tornando-se o tratamento de escolha universalmente aceito.

Como último recurso, os governos poderiam emitir "licenças compulsórias" que lhes permitiriam fabricar ou importar genéricos em um momento de crise sem consultar o detentor da patente. Embora a licença geralmente garanta uma taxa de royalty de cerca de $1 \%$ das vendas genéricas para o dono da patente, a Tailândia e o Brasil ainda baixaram preços de modo significativo quando, recentemente, emitiram licença compulsória para o Efavirenz e importaram um genérico produzido na Índia. O remédio é usado por mais de 75 mil brasileiros, e ativistas aplaudem essa jogada como importante avanço na ampliação do acesso a tratamentos mais novos e mais caros. Mas emitir licenças compulsórias não é solução sustentável, no longo prazo. Devido a restrições recentes na importação de genéricos, o licenciamento compulsório exige que os países tenham capacidade interna de produção farmacêutica, o que significa que a maioria dos países de poucos recursos não pode utilizar essa ínfima flexibilidade embutida no regime de propriedade intelectual reinante.

\section{A judicialização do direito à saúde}

Por todo o Brasil, há doentes buscando o judiciário para conseguir remédios prescritos. O modelo de demanda de acesso a terapias de AIDS baseado em direitos "migrou" para outras doenças e outros grupos de doentes. Mesmo tendo o programa de HIV/AIDS mais avançado do mundo em desenvolvimento, o Brasil vê muitos de seus cidadãos indo a farmácias locais apenas 
para descobrir que faltam medicamentos essenciais nas prateleiras. O Brasil é também um dos mercados farmacêuticos que mais rapidamente crescem no mundo. Cada vez mais os médicos receitam e os doentes pedem remédios novos, alguns deles com benefícios questionáveis. Diante do alto custo ou da falta de medicamentos, muitas pessoas estão processando o governo a fim de obtê-los (Biehl et al., 2009).

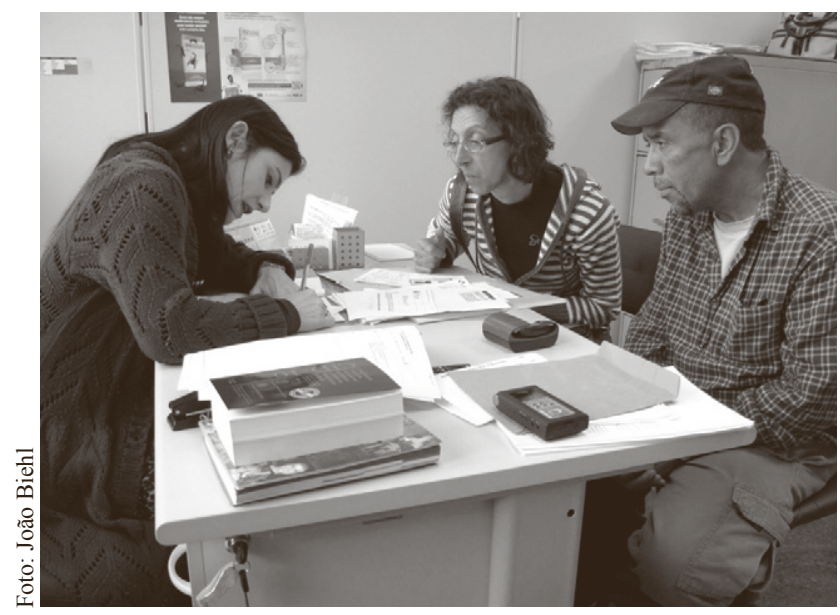

Figura 7. Paciente e esposa abrindo um processo pelo direto à saúde com uma defensora pública.

Embora as ações judiciais garantam acesso para milhares de pessoas, essa judicialização do direito à saúde gera enormes dificuldades fiscais e administrativas e pode aumentar as desigualdades na assistência médica. Em 2006, 6800 ações médico-judiciais chegaram à Procuradoria Geral do Estado do Rio Grande do Sul. Para se ter uma ideia do aumento, foram registradas 1126 dessas ações em 2002. Em 2008, estavam chegando à procuradoria, em média, 1200 novos casos por mês. Nesse mesmo ano, o estado de 11 milhões de habitantes gastou US\$ 30,2 milhões em medicamentos obtidos por ordem judicial. Esse gasto representa $22 \%$ do total despendido em produtos farmacêuticos naquele ano e $4 \%$ do orçamento anual projetado para a saúde. Cerca de um terço das demandas atuais envolvem medicamentos de alto custo não 
fornecidos pelo sistema público de saúde. Essas demandas certamente explicam em grande parte as despesas do estado.

Curiosamente, a decisão do Supremo Tribunal em 2000, sobre um paciente de AIDS que exigia o acesso a uma nova droga antirretroviral, continua a informar as decisões de atendimento farmacêutico em tribunais estaduais e federais. Em sua decisão, o Ministro Celso de Mello argumentou que o programa de assistência farmacêutica à AIDS era a concretização do dever constitucional do governo de implementar políticas garantidoras da saúde da população. Como incorporação concreta da necessidade de "normas programáticas", o programa de AIDS adquiriu um valor judicial inerente na decisão de Mello. Assim que os necessitados tenham medicamentos, de acordo com Mello, a responsabilidade legal do governo de implementar normas programáticas que assegurem a saúde estará cumprida e deixará de ser "uma promessa constitucional inconsequente". Nessa interpretação, a garantia imediata do direito à saúde através de medicamentos contorna questões sobre as limitações de políticas, conhecimento ou recursos.

Entrevistas recentes revelam visões conflitantes. Muitos juízes e defensores públicos que trabalham nos casos de direito à saúde acham que estão respondendo às falhas do Estado em fornecer os medicamentos necessários, e alguns juízes admitem a falta de conhecimento médico especializado para tomar decisões informadas de forma consistente. Os administradores alegam que o judiciário está excedendo o seu papel, embora alguns reconheçam que, por causa desses casos, a distribuição de vários fármacos tem aumentado. As organizações de pacientes têm um papel altamente contestado. Funcionários afirmam que pelo menos algumas organizações são financiadas por companhias farmacêuticas ávidas para vender medicamentos de alto custo ao governo. Os pacientes encontram um sistema jurídico sobrecarregado e desconcertante, no qual as decisões liminares de acesso a medicamentos que salvam vidas precisam ser renovadas periodicamente, geralmente resultando na interrupção de tratamentos e em complicações médicas secundárias.

As apostas são altas e o debate é acalorado. Quais são as implicações institucionais e políticas de converter o judiciário em executor maior do Estado? Seriam os tribunais uma verdadeira voz alternativa para aqueles que normalmente são marginalizados do processo político? O que estamos vendo é uma nova forma de "politização" do direito à saúde que o torna mais acessível, ou uma erosão dele, que o torna mais privatizado e desigual? 


\section{Frágeis ilhas de hospitalidade}

Finalmente isso me traz de volta à Caasah. "Se você olhar com cuidado, nada mudou", contou-me uma Celeste fatigada, durante minha última visita, em junho de 2005. A Caasah ainda era o único lugar em Salvador que prestava assistência sistemática a doentes de AIDS pobres que tiveram alta dos hospitais públicos. "Alguns pacientes voltam para suas famílias. Outros voltam para as ruas. A doença continua se espalhando e o governo finge não saber."

No pavilhão de AIDS do estado, a Dra. Nanci lamentou, "Ainda estamos cheios de pacientes moribundos. A diferença agora é que eles vêm do interior, onde não foi criando nenhum serviço novo. $\mathrm{O}$ acesso a terapias foi democratizado, mas a saúde não foi." Muitos médicos não colocam dependentes químicos e indivíduos sem teto em terapia antirretroviral. Dizem que não há garantia de que eles continuarão o tratamento e que estão preocupados com a criação de resistência viral aos antirretrovirais. Assim, diante de um crescente discurso de direitos humanos e possibilidades farmacêuticas, somos aqui confrontados com os limites básicos de infraestruturas onde uma nova vida com AIDS pode ser atingida, mas apenas de maneira limitada.

Do grupo inicial de 22 pacientes da Caasah com quem eu tinha trabalhado em 1997, sete ainda estavam vivos em 2005 - entre eles Evangivaldo. Sua sobrevida era obviamente uma consequência dos avanços tecnológicos, Celeste argumentou, "mas não teria acontecido se eles não tivessem aprendido a se cuidar". Afinal de contas, ela afirmou, a adesão ao tratamento "depende de cada pessoa e exige enorme força de vontade". Contudo, longe de representar uma vitalidade natural, essa vontade de viver tem de ser fabricada e expressa no mercado e nos mundos médicos locais por aqueles que têm condições, por mais limitadas que sejam, de fazê-lo. Todos os sobreviventes de AIDS com quem trabalhei tinham criado frágeis ilhas de hospitalidade nas quais podiam habitar suas vidas inesperadas. Todos tinham um lugar que eles chamavam de lar, uma pequena renda regular e algum tipo de rede social. Sempre que necessário, podiam ainda recorrer à Caasah. Esse laço institucional, por mais tênue que agora fosse, continuava sendo vital para eles.

Ter alguém para quem viver e por quem ser desejado era também uma linha constante em suas narrativas. "Fátima teve um infarto", Evangivaldo me disse na última vez que o vi: "Ela sofre porque não pode ajudar. Mas eu digo a ela que o mais importante é ela estar viva, que eu não me importo de ser o 
homem e a mulher da casa. Deus conhece as qualidades de cada um de nós. Quem está mais forte agora tem de ajudar o mais fraco. O que importa é ter uma vida digna e saúde para ver Juliana crescer. O que eu tenho a dizer é isto."

Sem dúvida, o Brasil teve uma queda acentuada na mortalidade de AIDS. Contudo, da perspectiva dos pobres urbanos, a política de tratamento de AIDS não é necessariamente uma forma inclusiva de assistência médica. Os serviços locais de triagem e tratamento de AIDS e os direitos sociais e econômicos para os mais pobres são, na melhor das hipóteses, esporádicos. O Brasil, que inovou no acesso ao tratamento como um direito humano, precisa definir e implementar mais completamente um direito à saúde que transcenda medicamentos e exigências individuais, e garantir que a assistência médica e a prevenção primárias sejam robustas o suficiente para reduzir a vulnerabilidade à doença. Da mesma forma, está em questão uma reconsideração da relação sistêmica entre pesquisa farmacêutica, interesse comercial e assistência à saúde pública. Deveríamos pensar numa solução mais sustentável para os obstáculos colocados pela patenteabilidade e o controle comercial sobre a ciência e a assistência médica de base. Uma parte da solução pode residir na partilha abrangente de informação e tecnologia entre países setentrionais - um paradigma que permitiria aos países mais pobres desenvolver programas de avaliação de tecnologia de saúde, juntar seu know-how manufatureiro e unir-se na luta por preços mais justos.

Os ex-residentes da Caasah são o novo povo da AIDS. Por todos os critérios, eles ultrapassaram os limites de seu destino. Agora que estão recebendo tratamento, Evangivaldo e muitos outros recusam a condição de restolhos. E eles enfrentam o desafio diário de transformar investimentos médicos em capital social e possibilidade de renda. Eles vivem entre momentos, entre espaços, catando recursos. A cada volta eles precisam considerar o próximo passo a ser tomado para garantir a vida. Sua força é a da imanência. Com esse povo, "podeis aprender que o homem é sempre a melhor medida. Mais: que a medida do homem não é a morte, mas a vida".

Ajustando-se continuamente à realidade de vidas e mundos contemporâneos, o trabalho antropológico tem o potencial da arte: invocar potenciais humanos negligenciados e expandir os limites de compreensão e imaginação - um povo ainda por vir. Também está em jogo o nosso poder formativo de gerar um "nós", uma audiência e comunidade política engajada, que não existiu anteriormente - assinalando o potencial de o nosso ofício tornar-se uma força mobilizadora neste mundo. 


\section{Referências}

ADAMS, V.; NOVOTNY, T.;LESLIE, H. Global health diplomacy (editorial). Medical Anthropology, v. 12, n. 4, p. 315-323, 2008.

AGAMBEN, G. Homo sacer: sovereign power and bare life. Stanford: Stanford University Press, 1998.

AGAMBEN, G. Remnants of Auschwitz: the witness and the archive. New York: Zone Books, 1999.

BANERJEE, A. V. 'New Development Economics' and the challenge to theory. Economic and Political Weekly, p. 4340-4344, October 1st, 2005.

BANERJEE, A. V. Making aid work. Cambridge, MA: MIT Press, 2007.

BIEHL, J. Vita: life in a zone of social abandonment. Berkeley: University of California Press, 2005.

BIEHL, J. Will to live: AIDS therapies and the politics of survival. Princeton: Princeton University Press, 2007.

BIEHL, J. Drugs for all: the future of global AIDS treatment. Medical Anthropology, v. 27, n. 2, p. 1-7, 2008.

BIEHL, J.; MORAN-THOMAS, A. Symptom: subjectivities, social ills, technologies. Annual Review of Anthropology, n. 38, p. 267-288, 2009.

BIEHL, J.; LOCKE, P. Deleuze and the Anthropology of Becoming. Current Anthropology, v. 51, n. 3, p. 317-351, 2010. (with comments and a reply).

BIEHL, J. et al. The judicialisation of the right to health in Brazil. Lancet, n. 373 , p. $2182-2184,2009$.

BLEAKLEY, H. Economic effects of childhood exposure to tropical disease. American Economic Review, Paper and Proceedings, 2009.

BOURGOIS, P.; SCHONBERG, J. Righteous dopefiend. Berkeley: University of California Press, 2009. 
BRANDT, A. No magic bullet: a social history of venereal disease in the United States since 1880. New York: Oxford University Press, 1985.

BRITO, L. Mortalidade de negros é maior do que a de brancos. Folha Online, 3 ago. 2005. Disponível em: <http://www1.folha.uol.com.br/folha/cotidiano/ ult95u111617.shtml>. Acesso em: 4 ago. 2005.

CANGUILHEIM, G. The decline of the idea of progress. Economy and Society, v. 27 , n. 2/3, p. 313-329, 1998.

COLLIER, S. J.; ONG, A. Global assemblages, anthropological problems. In: ONG, A.; COLLIER, S. J. (Ed.). Global assemblages: technology, politics, and ethics as anthropological problems. Malden: Blackwell Publishing, 2005. p. 3-21.

COMAROFF, J. Beyond bare life: AIDS, (bio)politics, and the neoliberal order. Public Culture, v. 19, n. 1, p. 197-219, 2007.

CUETO, M. Cold war, deadly fevers: malaria eradication in Mexico, 19551975. Washington, D.C.: Woodrow Wilson Center Press; Baltimore: Johns Hopkins University Press, 2007.

DAS, V.; POOLE, D. (Ed.). Anthropology at the margins of the State. Santa Fe: SAR Press, 2004.

DEATON, A. Instruments of development: randomization in the tropics, and the search for the elusive keys to economic development. The Keynes Lecture, British Academy, 2009. Unpublished paper.

DELEUZE, G. Two regimes of madness: texts and interviews 1975-1995. Los Angeles: Semiotext(e), 2006.

DELEUZE, G.; GUATTARI, F. Kafka: toward a minor literature. Minneapolis: University of Minnesota Press, 1986.

DUFLO, E.; GLENNERSTER, R.; KREMER, M. Using randomization in development economics research: a toolkit. In: SCHULTZ, T. P.; STRAUSS, J. (Ed.). Handbook of development economics: vol. 4. Amsterdam: Elsevier, 2008. p. 3895-3962. 
EASTERLY, W. R. The white man's burden: why the West's efforts to aid the rest have done so much ill and so little good. Oxford: Oxford University Press, 2006.

EASTERLY, W. R. (Ed.). Reinventing foreign aid. Cambridge, MA: MIT Press, 2008.

ECKS, S. Pharmaceutical citizenship: antidepressant marketing and the promise of demarginalization in india. Anthropology \& Medicine, v. 12, n. 3, p. 239-254, 2005.

EPSTEIN, H. The invisible cure: Africa, the West, and the fight against AIDS. New York: Farrar, Straus and Giroux, 2007.

FARMER, P. Infections and inequalities: the modern plagues. Berkeley: University of California Press, 2001.

FARMER, P. Pathologies of power: health, human rights, and the new war on the poor. Berkeley: University of California Press, 2003.

FARMER, P. Challenging orthodoxies: the road ahead for health and human rights. Health and Human Rights, v. 10, n. 1, p. 5-19, 2008.

FASSIN, D. When bodies remember: experiences and politics of AIDS in South Africa. Berkeley: University of California Press, 2007.

FERGUSON, J. Global shadows: Africa in the neoliberal world order. Durham: Duke University Press, 2006.

FIDLER, D. Global health jurisprudence: a time of reckoning. Georgetown Law Journal, v. 96, n. 2, p. 393-412, 2008.

FISCHER, M. M. J. Anthropological futures. Durham: Duke University Press, 2009.

FOUCAULT, M. The history of sexuality. New York: Vintage Books, 1990.

FOUCAULT, M. Security, territory, population: lectures at the Collège de France 1977-1978. New York: Palgrave Macmillan, 2007. 
GARCIA, A. The elegiac addict: history, chronicity and the melancholic subject. Cultural Anthropology, v. 23, n. 4, p. 718-746, 2008.

GEERTZ, C. The world in pieces: culture and politics at the end of the century. In: GEERTZ, C. Available light: anthropological reflections on philosophical topics. Princeton: Princeton University Press, 2000. p. 218-263.

HACKING, I. Making up people. In: BIAGIOLI, M. (Ed.). The science studies reader. New York: Routledge, 1999. p. 161-171.

HECKMAN, J. J.; VYTLACIL, E. J. Econometric evaluation of social programs, part 2: using the marginal treatment effect to organize alternative econometric estimators to evaluate social programs, and to forecast their effects in new environments. In: HECKMAN, J. J.; LEAMER, E. E. (Ed.). Handbook of econometrics: volume 6B. Amsterdam: Elsevier, 2007. p. 4875-5143.

HIRSCHMAN, A. O. A bias for hope: essays on development and Latin America. New Haven: Yale University Press, 1971.

KREMER, M.; MIGUEL, E. The illusion of sustainability. The Quarterly Journal of Economics, p. 1007-1065, Aug. 2007.

KRISTOF, N. D. Attack of the worms. The New York Times, July 2, 2007. Disponível em: <http://select.nytimes.com/2007/07/02/opinion/02kristof. html $>$. Acesso em: 3 jul. 2007.

MELO NETO, J. C. Education by stone. New York: Archipelago Books, 2005.

MORAN-THOMAS, A. Disparity, paradox, ethnography: observations on the spread of diabetes in the developing world. Anthropology News, v. 50, n. 4, 2009. p. 34-54.

NGUYEN, V.-K. Antiretroviral globalism, biopolitics, and therapeutic citizenship. In: ONG, A.; COLLIER, S. J. (Ed.). Global assemblages: technology, politics, and ethics as anthropological problems. Malden, MA: Blackwell Publishing, 2005. p. 124-144.

PETRYNA, A. When experiments travel: clinical trials and the global search for human subjects. Princeton: Princeton University Press, 2009. 
PETRYNA, A.; LAKOFF, A.; KLEINMAN, A. (Ed.). Global pharmaceuticals: markets, practices, ethics. Durham: Duke University Press, 2006.

RABINOW, P.; ROSE, N. Biopower today. BioSocieties, n. 1, p. 195-217, 2006.

RAMIAH, I.; REICH, M. R. Public-private partnerships and antiretroviral drugs for HIV/AIDS: lessons from Botswana. Health Affairs, v. 24, n. 2, p. $545-551,2005$.

RANCIÈRE, J. Who is the subject of the rights of man? The South Atlantic Quarterly, v. 102, n. 2/3, p. 297-310, 2004.

REICH, M. R. Public-private partnerships for public health. Cambridge, MA: Harvard Center for Population and Development Studies, 2002

REYNOLDS WHYTE, S. et al. Treating AIDS: dilemmas of unequal access in Uganda. In: PETRYNA, A.; LAKOFF, A.; KLEINMAN, A. (Ed.). Global pharmaceuticals: markets, practices, ethics. Durham: Duke University Press, 2006. p. 240-262.

ROBINS, S. From "rights" to "ritual": AIDS activism in South Africa. American Anthropologist, v. 108, n. 2, p. 312-23, 2006.

SACHS, J. The end of poverty: economic possibilities for our time. New York: Penguin, 2005.

SAMSKY, A. Pharmaceutical philanthropy and global health: an anthropological study of practices and values shaping drug donation programs. Ph.D. Thesis. Princeton University, 2009.

SCHEPER-HUGHES, N. A talent for life: reflections on human vulnerability and resistance. Ethnos, v. 73, n. 1, p. 25-56, 2008.

SINGER, P. The life you can save: acting now to end world poverty. New York: Random House, 2009.

TODD, P. E.; WOLPIN, K. I. Assessing the impact of a school subsidy program in Mexico: using a social experiment to validate a dynamic behavioral model of child schooling and fertility. American Economic Review, v. 96, n. 5, p. 1384-1417, 2006. 
TSING, A. Friction: an ethnography of global connection. Princeton: Princeton University Press, 2004.

WHITMARSH, I. biomedical ambiguity: race, asthma, and the contested meaning of genetic research in the Caribbean. Ithaca: Cornell University Press, 2008.

Recebido em: 31/10/2010 Aprovado em: 30/11/2010 